\title{
Index to Volume 9
}

Ballman, W. AND WojtKowski, M. P. An estimate for the measure theoretic entropy of geodesic flows, 271

BLOKH, A. M. AND LyUBICH, M. YU. Non-existence of wandering intervals and structure of topological attractors of one dimensional dynamical systems 2. The smooth case, 751

Bonckaert, P., Dumortier, F. AND Van Strien, S. Singularities of vector fields on $\mathbb{R}^{3}$ determined by their first non-vanishing jet, 281

BOSE, C. J. Generalized baker's transformations, 1

BURNS, K. AND GERBER, M. Continuous invariant cone families and ergodicity of flows in dimension three, 19

BURns, K. AND Gerber, M. Real analytic Bernoulli geodesic flows on $\boldsymbol{S}^{2}, 27$

Connes, A. Compact metric spaces, Fredholm modules, and hyperfiniteness, $207 \dagger$

COWLING, M. AND ZIMMER, R. J. Actions of lattices in $\operatorname{Sp}(1, n), 221 \dagger$

DíAZ, L. J. AND VIANA, M. Discontinuity of Hausdorff dimension and limit capacity on arcs of diffeomorphisms, 403

DUFOUR, J.-P. Existence de cycles pour des multi-applications du cercle, 47

Dumortier, F. See Bonckaert, P., Dumortier, F. and Van Strien, S.

Feldman, J., Sutherland, C. E. And Zimmer, R. J. Subrelations of ergodic equivalence relations, $239 \dagger$

FERES, R. AND KATOK, A. Invariant tensor fields of dynamical systems with pinched Lyapunov exponents and rigidity of geodesic flows, 427

Friedland, S. AND Milnor, J. Dynamical properties of plane polynomial automorphisms, 67

Gerber, M. See Burns, K. AND Gerber, M.

Glasner, S. AND MAON, D. Rigidity in topological dynamics, 309

GoRA, P. AND SCHMITT, B. Un exemple de transformation dilatante et $C^{t}$ par morceaux de l'intervalle, sans probabilité absolument continue invariante, 101

Guivarc'H, Y. Propriétés ergodiques, en mesure infinite, de certains systèmes dynamiques fibrés, 433

HAMENSTÄDT, U. A new description of the Bowen-Margulis measure, 455

Hasselblat, B. A new construction of the Margulis measure for Anosov flows, 465

Host, B. AND Parreau, F. Homomorphismes entre systèmes dynamiques définis par substitutions, 469

KatoK, A. Vladimir Abramovich Rokhlin (23 August 1919 to 3 December 1984): Introductory note, 605

Katok, A. See Feres, R. AND Katok, A.

KATZNELSON, Y. AND ORNSTEIN, D. The differentiability of the conjugation of certain diffeomorphisms of the circle, 643

KATZNElson, Y. AND ORNSTEIN, D. The absolute continuity of the conjugation of certain diffeomorphisms of the circle, 681

KITCHENS, B. AND SCHMIDT, K. Automorphisms of compact groups, 691

KEEN, L. Topology and growth of a special class of holomorphic self-maps of $\mathbb{C}^{*}, 321$

KIM, K. H. AND Roush, F. W. Decidability of epimorphisms of dimension groups and certain modules, 479 
LESIGNE, E. Théorèmes ergodiques pour une translation sur une nilvariété, 115

LONGO, R. Restricting a compact action to an injective subfactor, 127

LYUBICH, M. YU. Non-existence of wandering intervals and structure of topological attractors of one dimensional dynamical systems: 1. The case of negative Schwarzian derivative, 737

Lyubich, M. Yu. See Blokn, A. M. AND Lyubich, M. Yu.

Maon, D. See Glasner, S. And Maon, D.

MARTIN, N. F. G. On ergodic properties of restrictions of inner functions, 137

MATSUOKA, T. The number of periodic points of smooth maps, 153

MEESTER, R. W. J. An algorithm for calculating critical probabilities and percolation functions in percolation models defined by rotations, 495

Milnor, J. See Friedland, S. ANd Milnor, J.

MOSHER, L. Equivariant spectral decomposition for flows with a $\mathbb{Z}$ action, 329

Nakanishi, T. A remark on R. Moeckel's paper 'Geodesics on modular surfaces and continued fractions', 511

Nogueira, A. Almost all interval exchange transformations with flips are nonergodic, 515

Nowicki, T. AND PRZYTYCKI, F. The conjugacy of Collet-Eckmann's map of the interval with the tent map is Holder continuous, 379

Ornstein, D. See Katznelson, Y. and Ornstein, D.

Parreau, F. See Host, B. and Parreau, F.

Posthumus, R. A. Homoclinic points and moduli, 389

Przytycki, F. See Nowicki, T. ANd Przytycki, F.

RAND, D. A. The singularity spectrum $f(\alpha)$ for cookie-cutters, 527

Roush, F. W. See KIM, K. H. AND Roush, F. W.

RudolPh, DANiel, J. AND Silva, CESAR E. Minimal self-joinings for nonsingular transformations, 759 .

ShishikURA, M. Trees associated with the configuration of Herman rings, 543

SCHMIDT, K. See KITCHENS, B. AND SCHMIDT, K.

SCHMITT, B. See Gora, P. AND SCHMITT, B.

Silva, Cesar, E. See Rudolph, Daniel J. and Silva, Cesar E.

SIMANYI, N. AND WOJTKOWSKI, M. P. Two-particle billiard system with arbitrary mass ratio, 165

Sutherland, C. E. See Feldman, J., Sutherland, C. E. and Zimmer, R. J.

SWIATEK, G. Endpoints of rotation intervals for maps of the circle, 173

TUNCEL, S. Subsystems, Perron numbers, and conf̧inuous homomorphisms of Bernoulli shifts, 561

Van Strien, S. See Bonckaert, P., Dumortier, F. and Van Strien, S.

VERSHIK, A. M. Vladimir Abramovich Rokhlin-A biographical tribute (23.8.1919-3.12.1984), 629

Viana, M. See Díaz, L. J. ANd Viana, M.

WeIss, B. On the work of V. A. Rokhlin in ergodic theory, 619

WEISS, H. Non-smooth geodesic flows and the earthquake flow on Teichmüller space, 571

WEISS, $H$. The geometry of measured geodesic laminations and measured train tracks, 587

WITTE, D. Rigidity of horospherical foliations, 191

Wojtkowski, M. P. See Ballman, W. and Wojtkowski, M. P.

Wojtkowski, M. P. See Simanyi, N. ANd Wojtkowski, M. P.

YUZVinSKY, S. Rokhlin's School on ergodic theory, 609

ZiMmer, R. J. See CoWling, M. AND ZimMER, R. J.

Zimmer, R. J. See Feldman, J., Sutherland, C. E. And Zimmer, R. 